\title{
CONTINUOUS SEPARATION OF SPHERICAL AND NON-SPHERICAL PARTICLES ON AN INCLINED ROTATING DISC
}

\author{
MASUNORI SUGIMOTO, KENICHI YAMAMOTO \\ AND JOHN C. WILLIAMS \\ Department of Chemical Engineering, Toyama University, \\ Takaoka 933
}

\begin{abstract}
On the basis of the assumption of the separation mechanism that the separation of spherical particles from the mixture containing non-spherical particles on an inclined rotating disc with a spiral scraper will be controlled by the number of the non-spherical particles in the separating zone on the disc, it is shown that the number of the non-spherical particles can be approximately predicted by the operating variables and that their effect on the efficiency will be determined by the value of the group $\left(n d_{p i}{ }^{2} \rho_{p i} / F_{i}\right)$ below the critical value of the disc inclinations and rotating speeds.

It is found experimentally that Newton's separation efficiency can be predicted from the equation in which the efficiency increases exponentially with the value of the group, regardless of the fraction of spherical particles in the mixture.
\end{abstract}

\section{Introduction}

In some industrial processes it is required to separate spherical particles from others that are ellipsoidal, tear drops, dumbbells or irregular in shape.

Carpenter and Deitz ${ }^{1)}$ were able to separate accurately spherical particles from a batch of glass beads which contained some slightly elliptical particles by using a rotating disc at a slight angle to the horizontal. The separation method depends on the fact that spheres will roll in a straight line, whereas non-spheres roll either in a circular path or not at all.

Riley $^{2)}$ has separated spherical particles from mixtures of particles which contained irregular or cylindrical particles or flakes on an inclined rotating disc. The apparatus was based on that of Carpenter and Deitz with slight modification.

In the work referred to above the experiments were carried out with laboratory scale apparatus to separate a small amount of the solid mixture, but no attempts were made to study the effect of operating conditions on the efficiency of separation nor to explain the mechanism of the process.

In the present work the effectiveness of separation for the continuous separation of spherical particles from mixtures which contain non-spherical particles is discussed.

The method considered uses an inclined rotating disc with a spiral scraper. It has been suggested in an

Received July 29, 1976. Correspondence concerning this article should be addressed to M. Sugimoto. J. C. Williams is at Postgraduate School of Studies in Powder Technology, University of Bradford, Yorkshire BD7 1DP, England. earlier publication ${ }^{33}$ that this device was useful for the continuous separation of mixtures.

\section{Experiments}

\section{1 Apparatus}

The apparatus developed for the present work for the continuous separation of spherical and non-spherical particles is based on that of Carpenter and Deitz, but with considerable modification of the scraper and feeder. The equipment used is shown in Fig. 1. The separation disc used was a glass plate of $50 \mathrm{~cm}^{\phi}$ in diameter and $3 \mathrm{~mm}$ in thickness with slightly roughen-

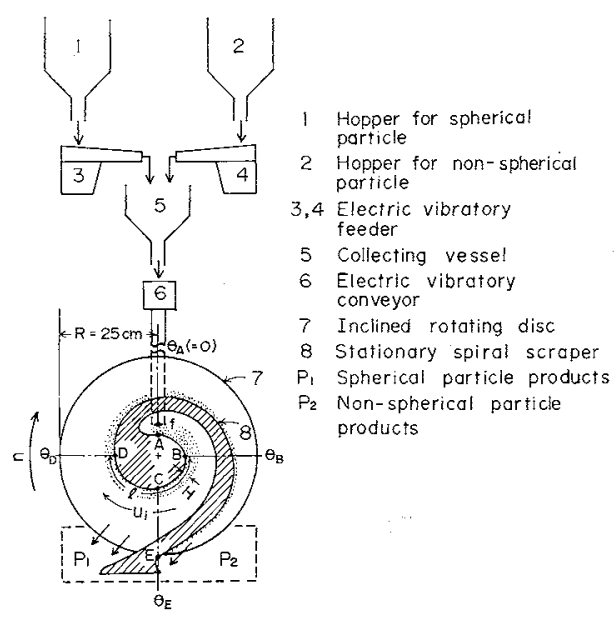

f; feed point, B-D; separating zone, D-E; conveying zone

Fig. 1 Schematic diagram of experimental apparatus and a separation model on an inclined rotating disc with a logarithmic spiral scraper 


\begin{tabular}{|c|c|c|c|c|}
\hline \multirow[b]{2}{*}{ Mixt. } & \multirow{2}{*}{$\begin{array}{rl}\text { Table } 1 & \mathbf{E x} \\
\text { Materials } & \end{array}$} & \multicolumn{2}{|c|}{ xperimental materials } & \multirow[b]{2}{*}{$\begin{array}{l}\text { Average } \\
\text { dia. } \\
\text { [cm] }\end{array}$} \\
\hline & & $\begin{array}{l}\text { Density } \\
{\left[\mathrm{g} / \mathrm{cm}^{3}\right]}\end{array}$ & $\begin{array}{c}\text { Size range } \\
{[\mathrm{cm}]}\end{array}$ & \\
\hline A & $\begin{array}{l}\text { Silica Sands* \& } \\
\text { Spherical Alumina }\end{array}$ & $\begin{array}{l}2.65 \\
1.20\end{array}$ & $0.238-0.336$ & 0.287 \\
\hline B & $\begin{array}{l}\text { Silica Sands* \& } \\
\text { Spherical Alumina }\end{array}$ & $\begin{array}{l}2.65 \\
1.20\end{array}$ & $0.336-0.400$ & 0.368 \\
\hline $\mathrm{C}$ & $\begin{array}{l}\text { Silica Sands* \& } \\
\text { Spherical Alumina }\end{array}$ & $\begin{array}{l}2.65 \\
1.20\end{array}$ & $0.400-0.476$ & 0.438 \\
\hline $\begin{array}{l}\mathrm{D} \\
* \mathrm{n}\end{array}$ & $\begin{array}{l}\text { Silica gel* \& } \\
\text { Spherical Silica gel } \\
\text { on-spherical particles }\end{array}$ & $\begin{array}{l}1.78 \\
1.96\end{array}$ & $0.238-0.336$ & 0.287 \\
\hline
\end{tabular}

ed surface. The disc was tilted at $7^{\circ}$ to the horizontal, because at that inclination the spherical particles can roll down nearly in a straight line, whereas the nonspherical particles used in this experiment can neither roll nor slide. The disc was mounted on a turn-table rotating at a selected constant speed.

A spiral scraper was devised for the present work, its purpose being to remove non-spherical particles from the separating zone, together with some spherical particles which had failed to roll off the disc. The spiral scraper was made of a plastic plate $3 \mathrm{~mm}$ in thickness. It was designed as a logarithmic spiral curve. The curve A, B, C, D and E (Fig. 1) of the spiral scraper used was given by formula;

$$
r=4.75 \exp (0.176 \theta) \quad[\mathrm{cm}]
$$

where $r$ is the radius vector and $\theta$ is the vectorial angle. In this scraper when $\theta=3 \pi$ [rad] the maximum radius vector was equal to the radius of the disc $(R=25.0 \mathrm{~cm})$.

The scraper was fixed and did not rotate with the disc but was kept in contact with the disc by a weight placed on the scraper.

To prevent changes in the component of the feed to the disc due to segregation of mixture during discharge from a container, two sets of the container and feeder were used, one for spherical particles and the other for non-spherical particles.

The feed rate of the particles was adjusted to a suitable value by the feeder for each of the types of particles and was kept constant during an experiment. A collecting vessel was placed so as to collect and blend the spherical and non-spherical particles and to feed them continuously to an electric vibratory conveyor, by which the binary mixture was rapidly fed onto the rotating disc.

\section{2 Experimental materials}

Four kinds of binary mixture were used in these experiments. Their properties are listed in Table 1. The components of each mixture were of different density, but their particle sizes were the same, so that the

\footnotetext{
* $\eta=\frac{\text { rate of spherical particles into product }}{\text { feed rate of spherical particles }}$ rate of non-spherical particles into product feed rate of non-spherical particles
}

separation could not have been effected by sieving. It was experimentally observed that all the spherical particles could roll down on the disc even though its inclination was very small, but the non-spherical particles could neither roll nor slide on the disc if its inclination to the horizontal was less than about $15^{\circ}$.

\subsection{Experimental procedure}

The feed rates of the spherical and non-spherical particles were adjusted to give the required mixture composition and total feed rate $F_{o}[\mathrm{~g} / \mathrm{min}]$, the latter being varied within the range 60 to 420 . The fraction of spherical particles in the mixture $M$ was defined as,

$$
M=F_{s} / F_{o}
$$

where $F_{s}$ is the feed rate of spherical particles. The experiments were carried out with various fractions in the range $1 / 8$ to $7 / 8$.

When the behaviour of the mixture fed onto the point $f$ on the disc as shown in Fig. 1 had apparently reached a steady state, the spherical and other particles which were separated and dropped down from the edge of the disc were sampled at positions $\mathrm{P}_{1}$ and $\mathrm{P}_{2}$.

The spherical particles were separated from these samples by hand. Newton's separation efficiency $\eta^{*}$ [-] was calculated from the results of the sample analysis. The holdup of the non-spherical particles remaining on the rotating disc was also weighed.

The speed of rotation of the disc was varied from 1 to $20 \mathrm{rpm}$. The effect of the friction force between the non-spherical particles and the rough surface of the glass plate used on the particles was greater than that of the centrifugal force acting on them at speed less than about $20 \mathrm{rpm}$, so that non-spherical particles were not able to roll or slide down towards the collecting position $P_{1}$. Most of the spherical particles of the mixture rolled down towards the position $\mathrm{P}_{1}$. The non-spherical particles and some spherical particles which were prevented from rolling down by the non-spherical particles were carried along the outside edge of the scraper by the rotation of the disc and were conveyed towards position $\mathrm{P}_{2}$ whose level was the lowest on the disc.

\section{4 Experimental results}

It was observed that non-spherical particles could hardly roll into the product of spherical particles in the present experiments. ${ }^{3 !}$

In order to investigate the effect of the fraction of spherical particles in the mixture $M$ on the separation efficiency $\eta, \eta$ is plotted against $\left(n / F_{i}\right)$, one of the usefull operating variables, in Fig. 2 , using mixture $\mathbf{A}$ and $\mathbf{D}$ for disc speeds ranging from 3 to $20 \mathrm{rpm}$ and various fraction $M . F_{i}$ is the feed rate of non-spherical particles in the mixture.

It is seen that although the fraction $M$ varies from $1 / 8$ to $7 / 8$ the results for the mixture A lie reasonably 


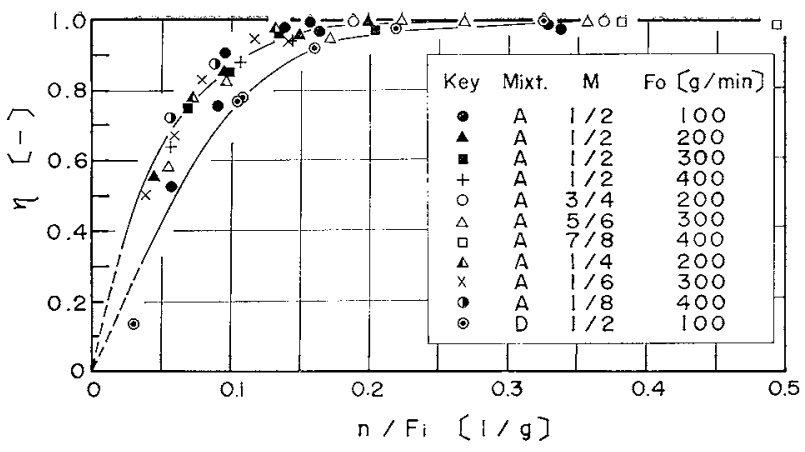

Fig. 2 Effect of fraction of spherical particles in mixture on the relationship between $\eta$ and $\left(n / F_{i}\right)$

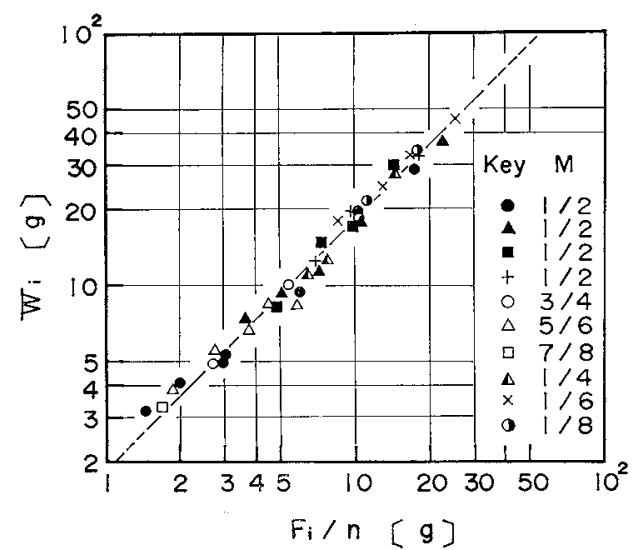

Fig. 3 Experimental relation between the holdup of nonspherical particles $W_{i}$ and $\left(F_{i} / n\right)$ in case of mixture $A$

well on a single line of exponential form. The results for the mixture $\mathbf{D}$ differing from the mixture $\mathbf{A}$ in density are shown in the same figure. These results are correlated by another exponential form. It is experimentally obvious that $\eta$ increases with $\left(n / F_{i}\right)$ regardless of $M$.

In Fig. 3, the holdup of the non-spherical particles remaining on the disc $W_{i}$ is plotted against $\left(F_{i} / n\right)$. The results were obtained by using a mixture $\mathbf{A}$ under the same experimental conditions as the above. It is seen that $W_{i}$ is inversely proportional to $\left(n / F_{i}\right)$ regardless of $M$.

From these experimental results, it is expected that $\eta$ increases as the amount of the non-spherical particles remaining on the disc decreases.

On the other hand, it was observed that the number of the spherical particles which were separated from the mixture depended on the number of the non-spherical particles remaining in the separating zone from $B$ to $D$ along the edge of the spiral scraper on the disc.

\section{Discussion}

\section{1 Separation modeI}

In order to discuss the mechanism of separation and to investigate the effect of operating conditions on the separation efficiency of the inclined rotating disc with a spiral scraper, a model of the separation process is proposed in this paper. In this separation model, it is assumed that the binary mixture of spherical and non-spherical particles should fulfill the following requirements: (i) The spherical particles are not so large in size and in density as they can roll over or push aside the non-spherical particles on the disc. (ii) The angle of the inclination and the speed of rotation of the disc are not large enough for the nonspherical particles to roll or slide but large enough for the spherical particles to roll down nearly in a straight line.

The maximum values of the inclination angle and the disc speed at which neither rolling nor sliding of the non-spherical particles occurs are referred to as the critical angle of inclination and the critical speed of rotation respectively. The present discussion applies only to the inclination and speed below the critical values.

When the spherical particles separate from the mixture, they will be prevented from rolling down by the non-spherical particles remaining on the disc.

The separation efficiency, therefore, depends on the holdup of the non-spherical particles on the disc and on the number of non-spherical particles in the separation zone.

The holdup and the number of the non-spherical particles can be obtained from a material balance equation as follows:

The zone B-D on the disc is the separating zone. $\mathrm{D}-\mathrm{E}$ is the conveying zone as shown in Fig. 1.

When non-spherical particles are fed onto f,

$$
F_{i}=u_{i} \frac{w_{i}}{l}=H u_{i}{ }^{-} w_{s}
$$

where $u_{i}$ is the average transporting velocity of the particles in the separating zone B-D (from $\theta=\theta_{B}$ to $\theta_{D}$ ) and is represented as a function of the mean velocity of the particles $u_{\theta i}$ at $\theta=\theta^{*}$,

$$
u_{i}=\frac{1}{\theta_{D}-\theta_{B}} \int_{\theta_{B}}^{\theta_{D}} u_{\theta i} d \theta
$$

$w_{i}$ is the weight of the holdup of the particles in the zone $[\mathrm{g}], l$ and $H$ are the average length and width of the zone occupied by the non-spherical particles respectively $[\mathrm{cm}]$ and $s$ is the area of the zone occupied by the particles $\left[\mathrm{cm}^{2}\right]$, where $s=l H$. Therefore, $w_{i} / s$ is the weight of the particles per unit area on the separating zone.

When each unit area in the separating zone contains $N_{i}$, the number of the non-spherical particles of the

* When it can be assumed that a particle is removed at a constant angular velocity $\omega_{i}$ along a logarithmic spiral scraper having the angle $\Phi$ which the tangent at any point of the curve makes with the radius vector at that point, $u_{\theta}^{\prime}$ of the particle is represented,

$$
u_{\theta}^{\prime}=\omega_{i} r / \sin \Phi
$$


volume shape factor $\phi_{v i}$, of $\rho_{p i}$ and $d_{p i}$, the following equations are given by the number of the particles $\delta_{h i}$ and $\delta_{r i}$ in the direction of the bed depth and of the disc radius respectively.

$$
N_{i}=\delta_{h i} / d_{p i}^{2}
$$

and

$$
H=\delta_{r i} \cdot d_{p i}
$$

so that

$$
w_{i} / s=\phi_{v i} d_{p i}^{3} \rho_{p i} N_{i}=\phi_{v i} d_{p i} \rho_{p i} \delta_{h i}
$$

Substituting Eqs. (3), (4) and (5) into Eq. (1),

$$
\begin{aligned}
& F_{i}=\phi_{v i} d_{p i}^{2} \rho_{p i} u_{i} \delta_{h i} \delta_{r i} \\
& \delta_{h i} \delta_{r i}=F_{i} /\left(\phi_{v i} d_{p i}^{2} \rho_{p i} u_{i}\right)
\end{aligned}
$$

The $\left(\delta_{h i} \cdot \delta_{r i}\right)$ is proportional to the dimensionless group $\left(F_{i} / \phi_{v i} d_{p i}^{2} \rho_{p i} u_{i}\right) . \quad \delta_{h i}$ and $\delta_{r i}$ will be able to represent the amount of the non-spherical particles impeding the separation of spherical particles from the mixture in the direction of particle bed depth and of the disc radius respectively, although $\delta_{r^{i}}$ is larger than $\delta_{h i}(\simeq 1)$ in many cases. It is, therefore, to be expected that increasing the value $\left(\delta_{h i} \cdot \delta_{r i}\right)$ will reduce the separation efficiency $\eta$. $\eta$ will increase as $\left(F_{i} / \phi_{v i} d_{p i}^{2}\right.$ $\rho_{p i} u_{i}$ ) decreases, provided that the centrifugal force acting on the non-spherical particles is insufficient to make them slide over the disc.

Since it is very difficult to measure $u_{i}$ experimentally, however, it is necessary to find some relationship between $u_{i}$ and the disc speed $n$. $u_{i}$ will depend on $n$. The form of the relationship between $u_{i}$ and $n$ cannot be predicted but must be established.

The total holdup $W_{i}$ is given by the mean transporting velocity of the particles on the disc $U_{i}$ (A to E).

$$
W_{i}=F_{i} \bar{t}=F_{i}\left(L / U_{i}\right)
$$

where $L$ is the average length of the path of the particles along the scraper and is constant in the present work. $\quad \bar{t}$ is the mean residence time of the particles and $U_{i}$ is represented on referring to Fig. 1,

$$
U_{i}=\frac{L}{\bar{t}}=\frac{1}{\theta_{E}-\theta_{A}} \int_{\theta_{A}}^{\theta_{E}} u_{\theta i} d \theta
$$

It must be remembered that $W_{i}$ is proportional to $\left(F_{i} / n\right)$ experimentally as shown in Fig. 3.

$$
W_{i}=k\left(F_{i} / n\right)
$$

where $k$ is constant $[-]$.

Then, from Eqs. (8) and (10).

$$
U_{i}=(L / k) n
$$

Since it can be considered that the mean velocity of non-spherical particles $u_{i}$ in the separating zone will be proportional to $U_{i}$ during their stay on the disc under a constant operating condition, the following equation is obtained;

$$
u_{i}=K^{\prime} n
$$

where $K^{\prime}$, including $L$, is constant [cm].

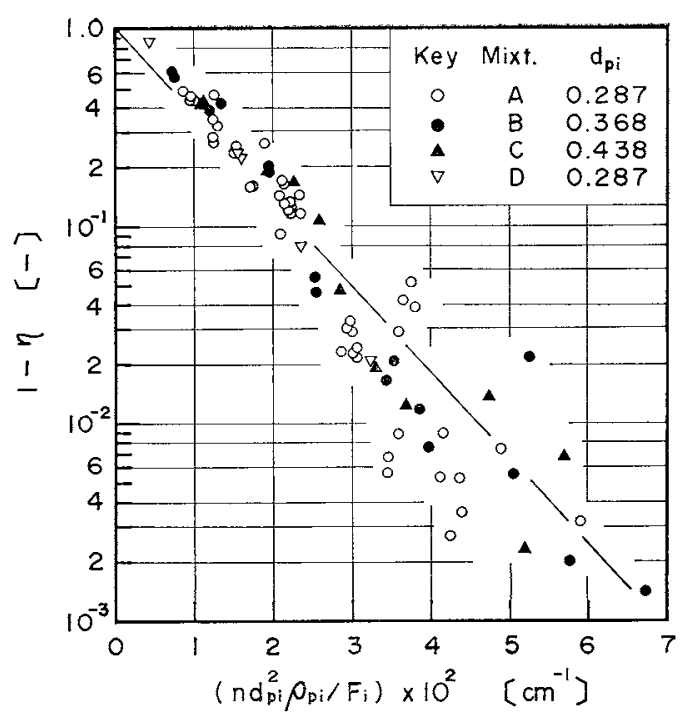

Fig. 4 Final correlation between $(1-\eta)$ and $\left(n d_{p i}^{2} \rho_{p i} / F_{i}\right)$

Substituting Eq. (12) into (6);

$$
\begin{aligned}
& F_{i}=K^{\prime} \phi_{v i} d_{p i}^{2} \rho_{p i} n \delta_{h i} \delta_{r i} \\
& \frac{1}{\delta_{h i} \delta_{r i}}=\left(K^{\prime} \phi_{v i}\right)\left(\frac{n d_{p i}^{2} \rho_{p i}}{F_{i}}-\right)
\end{aligned}
$$

The value of the group $\left(n d_{p i}^{2} \rho_{p i} / F_{i}\right)\left[\mathrm{cm}^{-1}\right]$ affects that of $\left(\delta_{h i} \cdot \delta_{r i}\right)$ and can be determined from the known operating conditions. The value of $K^{\prime}[\mathrm{cm}]$ will depend on the friction force between the non-spherical particles and the disc surface, and on the shape and wall roughness of the scraper.

\section{2 Effect of operating variables on $\eta$}

It is expected from Eq. (14) that the separation efficiency $\eta$ increases with $\left(n d_{p i}^{2} \rho_{p i} / F_{i}\right)$ on an inclined rotating disc below the critical values of the disc inclination and speed, because the increase of the group brings about the decrease of $\left(\delta_{h i} \cdot \delta_{r i}\right)$. It is possible to explain the Carpenter's experimental results from Eq. (14).

All the experimental results obtained at various rotation speeds for different component mixtures are shown in Fig. 4. The $(1-\eta)$ is plotted against the value of the group $\left(n d_{p i}^{2} \rho_{p i} / F_{i}\right)$ on a semilogarithmic graph paper.

These results lie approximately on a single straight line for three different sizes of non-spherical particles of alumina/silica sand mixture, although some of results scatter in lower value of $(1-\eta)$ which may be affected by rolling of a few non-spherical particles into the spherical products. Other experimental results for mixture $\mathbf{D}$ differing in density of particles lie on the same line as the results of mixture $\mathbf{A}, \mathbf{B}$ and $\mathbf{C}$.

The final correlation of the results can, therefore, be written:

$$
\eta=1-\exp K\left(n d_{p i}^{2} o_{p i} / F_{i}\right)
$$

where $K$ is constant $[\mathrm{cm}]$ and is $\left(-10^{2}\right)$ in the present 
experiments. In general the value of $K$ will depend on the coefficient of the friction between the nonspherical particles and the surface of the disc, and on the shape and wall roughness of the scraper. $K$ contains also the volume shape factor of non-spherical particles.

\section{Conclusion}

On the basis of the assumption that the separation efficiency of an inclined rotating disc with a spiral scraper for spherical particles will be controlled by the number of the non-spherical particles of the mixture in the separating zone, it is shown that the number of the non-spherical particles can be predicted from the operating variables and that their effect on the efficiency will be determined by the value of the group $\left(n d_{p i}^{2} \rho_{p i} / F_{i}\right)$, regardless of the component of the feed.

It is found experimentally that Newton's efficiency can be calculated from Eq. (15).

\begin{tabular}{|c|c|}
\hline \multicolumn{2}{|c|}{ Nomenclature } \\
\hline$d_{p}$ & $=$ average particle diameter \\
\hline$F$ & $=$ feed rate \\
\hline$H$ & $\begin{array}{c}=\text { average width of the separating zone } \\
\text { occupied by non-spherical particles }\end{array}$ \\
\hline$K, K^{\prime}$ & $=$ constant \\
\hline$k$ & $=$ constant \\
\hline$L$ & $\begin{aligned}= & \text { average length of the particle bed along } \\
& \text { the scraper on the disc from } A \text { to } E\end{aligned}$ \\
\hline$l$ & $\begin{array}{l}=\text { average length of the separating zone } \\
\text { occupied by non-spherical particles } \\
\text { from } B \text { to D }\end{array}$ \\
\hline$M$ & $\begin{aligned}= & \text { fraction of spherical particles in mixture } \\
& \text { (by weight) }\end{aligned}$ \\
\hline
\end{tabular}
$[\mathrm{g} / \mathrm{min}]$

[cm]

[cm]

[-]

[cm]

[cm]

\begin{tabular}{|c|c|c|c|}
\hline$n$ & $=$ & speed of rotation & [rpm] \\
\hline$N$ & $=$ & number of particles per unit area & {$\left[\mathrm{cm}^{-2}\right]$} \\
\hline$r$ & $=$ & radius vector & [cm] \\
\hline$s$ & $=$ & $\begin{array}{l}\text { area of the separating zone occupied by } \\
\text { non-spherical particles }\end{array}$ & {$\left[\mathrm{cm}^{2}\right]$} \\
\hline $\bar{t}$ & $=$ & $\begin{array}{l}\text { mean residence time of particles along } \\
\text { the scraper on the disc }\end{array}$ & {$[\mathrm{min}]$} \\
\hline$U$ & $=$ & $\begin{array}{l}\text { average transpotting velocity of particles } \\
\text { from } A \text { to } E \text { on the disc }\end{array}$ & {$[\mathrm{cm} / \mathrm{min}]$} \\
\hline$u$ & $=$ & $\begin{array}{l}\text { average transporting velocity of particles } \\
\text { in the separating zone }\end{array}$ & {$[\mathrm{cm} / \mathrm{min}]$} \\
\hline$u_{\theta}$ & $=$ & $\begin{array}{l}\text { average transporting velocity of particles } \\
\text { at } \theta=\theta\end{array}$ & {$[\mathrm{cm} / \mathrm{min}]$} \\
\hline$W$ & $=$ & weight of particles on the disc & [g] \\
\hline$w$ & $=$ & weight of particles in the separating zone & e \\
\hline$\delta_{h}$ & & $\begin{array}{l}\text { number of particle layer in the bed of } \\
\text { separating zone }\end{array}$ & \\
\hline$\delta_{r}$ & $=$ & $\begin{array}{l}\text { number of the particles arranged in the } \\
\text { direction of the disc radius in the zone }\end{array}$ & \\
\hline$\eta$ & $=$ & Newton's separation efficiency & {$[-]$} \\
\hline$\theta$ & $=$ & vectorial angle & [rad.] \\
\hline$\phi_{v}$ & $=$ & volume shape factor & {$[-]$} \\
\hline$\rho_{p}$ & $=$ & particle density & {$\left[\mathrm{g} / \mathrm{cm}^{3}\right]$} \\
\hline
\end{tabular}

$\langle$ Subscripts〉 [rpm]

$\left.\mathrm{cm}^{-2}\right]$

[cm]

$\left[\mathrm{cm}^{2}\right]$

$[\mathrm{min}]$ $\mathrm{m} / \mathrm{min}]$

$\mathrm{m} / \mathrm{min}]$

[g]

[一]

$\left.\mathrm{g} / \mathrm{cm}^{3}\right]$

$$
\begin{aligned}
{[\mathrm{cm}] } & i, s, o \quad= \\
\mathrm{g} / \mathrm{min}] & \text { value for non-spherical, spherical particles } \\
& \text { and mixture, respectively. }
\end{aligned}
$$

$A, B, C, D, E=$ value for the point on a disc

\section{Literature Cited}

1) Carpenter, F. G. and V. R. Deitz: J. Research N.B.S., 47, 139 (1951).

2) Riley, G. S.: Powder Technol., 2, 315 (1968).

3) Sugimoto, M. and K. Yamamoto: J. Res. Ass. of Powder Technol., Jpn., 8, 426 (1971).

(A part of this paper was presented at the 5th Autumn Meeting of The Soc. of Chem. Engrs., Japan, at Osaka, October, 7, 1971.) 